\title{
Analysis of Liver Function Difference in Severe and Non-severe COVID-19 Patients
}

\section{Yufeng Liu}

Anhui Provincial Hospital

Lei Li

Anhui Provincial Hospital

Shouwei Jiang

Anhui Provincial Hospital

Yao Liu

Anhui Provincial Hospital

Jiabei Wang

Anhui Provincial Hospital

Lianxin Liu ( $\square$ liulx@ustc.edu.cn )

Department of Hepatobiliary Surgery, Anhui Province Key Laboratory of Hepatopancreatobiliary Surgery, The First Affiliated Hospital of USTC, Division of Life Sciences and Medicine, University of Science and Technology of China, Hefei, Anhui, 230001, China https://orcid.org/0000-0002-3535-6467

Keywords:

Posted Date: October 22nd, 2020

DOl: https://doi.org/10.21203/rs.3.rs-95018/v1

License: (c) (1) This work is licensed under a Creative Commons Attribution 4.0 International License.

Read Full License 


\section{Abstract}

The authors have requested that this preprint be removed from Research Square. 